\title{
Microcrédito y pobreza: su relación con el desarrollo endógeno local
}

\author{
Microcredit and poverty: its relationship \\ with local endogenous development
}

\section{Resumen}

Artículo de investigación.

Fecha de recepción: 02/02/2020

Fecha de devolución: 09/07/2020

Fecha de aceptación: 25/07/2020

Fecha de publicación: 08/08/2020

\section{Diego Alfonso Ricardo Buelvas \\ Universidad de Sucre. \\ Sincelejo. (Colombia) \\ diego.ricardo@unisucre.edu.co}

\author{
León Julio Arango Buelvas \\ Universidad de Sucre. \\ Sincelejo. (Colombia) \\ leon.arango@unisucre.edu.co
}

\section{Ramón José Taboada Hernández \\ Universidad de Sucre. \\ Sincelejo. (Colombia) \\ ramon.taboada@unisucre.edu.co}

Para citar este artículo:

Ricardo, D., Arango, L. \& Taboada, R. (2020).

Microcrédito y pobreza: su relación con el desarrollo endógeno local. Económicas CUC, 41(2), 237-252. DOI: https://doi.org/10.17981/econcuc.41.2.2020.Econ.5
El sistema económico de un país se encuentra estrechamente relacionada con la pobreza, en este sentido, el objeto de la presente disertación es el análisis de la investigación se centra en la fundamentación teórica de los programas de microcrédito como estrategia para mejorar las condiciones de pobreza del sector de la población de escasos recursos económicos, considerando que tales programas incluyen en sus metas beneficiar tanto a individuos como empresas relacionadas con procesos productivos sin acceso a financiación bancaria. Los microcréditos en el desarrollo endógeno de una población determinada, se relacionan con el tema de las microfinanzas y su importancia en el desarrollo local de un territorio. El desarrollo de la investigación tiene como soporte la revisión documental y se utiliza como metodología la investigación descriptiva; como resultado del proceso investigativo se evidenció la importancia del microcrédito entre personas vulnerables económicamente y su función como fuente facilitadora de capital inicial de trabajo orientado a satisfacer las necesidades de financiamiento de micro-negocios, como medio de apoyo para ayudar a las personas a salir de la pobreza.

Palabras clave: Microcrédito; necesidad; pobreza; desarrollo endógeno; subdesarrollo; microfinanzas

\begin{abstract}
The economic system of a country is closely related to poverty, in this sense, the object of this dissertation is the analysis of the research focused on the theoretical foundation of microcredit programs as a strategy to improve the poverty conditions of the low-income sector of the population, considering that such programs include in their goals to benefit both individuals and companies related to production processes without access to bank financing. Microcredits in the endogenous development of a given population are related to the issue of microfinance and its importance in the local development of a territory. The development of the research is supported by documentary review and descriptive research is used as methodology; As a result of the investigative process, the importance of microcredit among economically vulnerable people and its role as a facilitator of initial working capital aimed at satisfying the needs of micro-business financing, as a means of support to help people to get out of poverty.

Keywords: Microcredit; need; poverty; endogenous development; underdevelopment; microfinance
\end{abstract}




\section{INTRODUCCIÓN}

Uno de los temas de mayor preocupación en cualquier sistema económico es el relacionado con la pobreza, el cual tiene connotaciones económicas con arraigamientos sociales, por lo tanto, requiere la intervención estatal y el concurso de acciones y programas con diversos actores de la economía. En Colombia hay dos formas de medir la pobreza: la pobreza monetaria y la pobreza multidimensional. La primera distingue entre pobreza y pobreza extrema, mientras que la segunda es el reflejo de la privación de distintas dimensiones que tienen los hogares (Departamento Nacional de Planeación-DNP, 2012). Privación misma que afecta a la sociedad desde muy diferentes elementos económicos (De La Torre, 2018; Casas, 2017).

De acuerdo con el Departamento Administrativo Nacional de Estadística (DANE, 2019), en términos de la pobreza monetaria, el porcentaje de personas clasificadas como pobres respecto al total de la población del país fue $27 \%$. Al hacerse la distribución por zonas se tiene que en las cabeceras la proporción fue $24,4 \%$ mientras que en los centros poblados y rural disperso alcanzó el 36,1\%, es decir, 1,5 veces la incidencia en las cabeceras. En cuanto a la pobreza monetaria extrema, la proporción de personas clasificadas como pobres extremas, respecto al total de la población colombiana fue de 7,2\%; por zonas geográficas correspondió al 4,9\% en las cabeceras y al $15,4 \%$ en los centros poblados y rural disperso, es decir, más de 3 veces la incidencia en las cabeceras.

En el departamento de Sucre la población pobre alcanzó el 41\%, mientras que la población situada en pobreza extrema fue de 7,5\% (DANE, 2019) Cabe indicar que niveles altos de pobreza tienden a generar problemas sociales graves y a afectar en forma negativa el ejercicio económico de un país considerando los bajos ingresos de la población y a los bajos niveles de demanda que en forma directa están asociados a la pobreza. En este sentido, Martínez (2006) considera que, para aliviar la pobreza, el crecimiento económico es necesario, pero no suficiente, siendo fundamental la combinación de políticas macroeconómicas que apoyen el crecimiento de las economías, con políticas microeconómicas que aborden las causas de la desigualdad en la distribución del ingreso. Según MacEwan (2010):

Los pobres son pobres porque carecen de poder, y no tienen poder porque son pobres (...) Una consecuencia de este enfoque es que, en lugar de hacer las cosas para los pobres, la política debe crear las condiciones en que los pobres pueden obtener poder, y cambiar su propia situación (p. 15).

Según Yunus (2000) una alternativa que podría ayudar a combatir la pobreza son las microfinanzas y más específicamente el microcrédito, el cual puede constituirse en una valiosa estrategia para el financiamiento o consecución de capital inicial de trabajo de unidades productivas y facilitar que personas que no tienen posibilidades de soportar con bienes o documentos los requerimientos que se exigen como garantía para la consecución de un crédito, puedan desarrollar ideas emprendedoras.

Rodríguez (2010) considera que una forma de contribuir con la reducción de la pobreza y de incrementar la inclusión social en poblaciones con niveles altos de vulnerabilidad, es a través del acceso a los servicios financieros en forma equitativa y con 
oportunidades para toda la población. Por tanto, se hace necesario que las instituciones financieras visionen formas de llegar a este tipo de poblaciones y les ayuden a desarrollar fuentes de ingresos para ellos y su núcleo familiar.

Lo anterior permite destacar la importancia de los programas de microcrédito en los territorios donde otorgan beneficios financieros a las personas que se encuentran en condiciones de vulnerabilidad económica. Sin ellos estas personas no habrían tenido la oportunidad de iniciar sus propias unidades productivas y es posible que no tuvieran una fuente de ingresos. Entiéndase como unidades productivas, aquellos negocios que crean los beneficiarios de los microcréditos (tiendas, peluquerías, chazas, panaderías, restaurantes, etc.), donde utilizan los recursos provenientes de los microcréditos como capital inicial de trabajo.

A pesar de la existencia de estos programas, el acceso al crédito continúa siendo uno de los grandes problemas para la población pobre (De Soto, 2008), por lo que se hace necesario que se desarrollen estrategias que faciliten la consecución de capital inicial de trabajo para personas en condiciones de vulnerabilidad.

\section{Metodología}

La investigación realizada es de tipo descriptivo en la que se expone el evento relacionado con el microcrédito, detallando sus características y la relación con el desarrollo endógeno local. Para su concreción se utilizó como técnica la revisión documental, lo que permite analizar en profundidad la compleja realidad económica y social del país en temas como el microcrédito y la pobreza. En este sentido se hace el análisis pertinente y la relación entre ellos.

\section{Realidades contextuales}

Como una opción a esta problemática fue presentada en la década de los 80 por el profesor Muhammad Yunus, Premio Nobel de la paz, quien inconforme con la brecha existente entre las teorías que explicaba en sus clases de Economía en la Universidad de Bangladesh y la realidad tanto económica como social del entorno que lo rodeaba, crea el Banco Grameen de Bangladesh. Una institución precursora en una estrategia nueva de lucha contra la pobreza, cuyas supuestas posibilidades de tener éxito provocan un entusiasmo generalizado. Corresponde al novedoso modelo de instituciones financieras de microcrédito que hoy se materializa en una gran cantidad de programas a nivel mundial, principalmente, en los países subdesarrollados (Muriel, 2000).

Estos mecanismos de financiación para la microempresa, han surgido especialmente en economías que se encuentran en vías de desarrollo para abordar la extrema pobreza, lo que se materializaba con la puesta en marcha de una serie de servicios financieros, entre los cuales se destaca el microcrédito. El objetivo social del microcrédito es la lucha contra la pobreza, pero con el pasar de los años su evolución ha llegado al punto que hoy día existen programas de microcrédito dirigidos no solo a la atención de la población más pobre, sino también destinados a financiar microemprendimientos que no están asociados, necesariamente, con la pobreza extrema, o a aquellos que han sido excluidos del sistema financiero formal (Foschiatto y Stumpo, 2006; Sanhueza, 2013). 


\section{Bases sobre las que se fundamenta el microcrédito}

El término microcrédito se deriva de los programas microfinancieros y estos a su vez buscan sentar las bases para que se den las condiciones apropiadas para un exitoso desarrollo endógeno en los territorios donde se aplican dichos programas; es una visión basada en el aprovechamiento que se hace de los recursos propios de las comunidades, con el fin de potenciarlos más que explotarlos, para el desarrollo de un territorio.

Para Garofoli (citado por Vergara, 2004, p. 40) el desarrollo endógeno está relacionado con la "capacidad para transformar el sistema socioeconómico; la habilidad para reaccionar a los desafíos externos, la promoción de aprendizaje social; y la habilidad para introducir formas específicas de regulación social a nivel local que favorecen el desarrollo de las características anteriores", es la habilidad para innovar a nivel local.

De lo planteado por Garofoli se puede inferir que el concepto en referencia, es una dimensión cualitativa basada en los recursos que se poseen; donde el conocimiento de lo que se tiene, constituye el punto de partida para el progreso, determinado por la red de relaciones entre los actores y sus actividades. Berezo (2005) plantea que de esta manera la dinámica del sistema sociocultural determina los factores de cambio, conducentes a diferentes oportunidades de desarrollo de acuerdo con las capacidades y características de la economía y la sociedad específica. He aquí lo fundamental de conocer lo relacionado con las culturas de emprendimiento que son particulares a cada región, asimismo tendencias en cuanto a innovación y en particular la gama de ideas que las élites de cada ente territorial tienen acerca del desarrollo (Vergara, 2004). Lo que está ligado a la adaptación de la sociedad a los cambios tecnológicos (Torres y Labarca, 2009), que los ayuden a diligenciar y administrar sus recursos, crear empleo y así mejorar sus condiciones de vida.

Esta es una estrategia para la acción, es decir, "la capacidad de las comunidades locales de liderar su propio proceso de desarrollo, unido a la movilidad de su potencial de desarrollo, es lo que permite dar a esta forma de desarrollo el calificativo de desarrollo endógeno" (Vázquez, 1999, p. 30). Esto sugiere a las comunidades locales, hacer lo posible por desarrollar sus potencialidades para generar tanto oportunidades de trabajo, como desarrollo económico y social a sus habitantes (Hernández, Ravina \& Chumaceiro, 2020).

El enfoque de desarrollo endógeno permite que se dé nueva interpretación concerniente a la situación que afrontan las regiones caracterizadas por la pobreza y desigualdad, identificando de paso otras potencialidades sociales acorde con las metas de cada región. "Cualquiera que sea la interpretación que se adopte, las políticas de desarrollo humano tienen que construirse a partir de factores económicos, sociales, ambientales, institucionales, políticos y culturales que se combinan de forma única en cada localidad, en cada territorio" (Vázquez, 2007, p. 55). El avance de las personas en forma integral dentro de las comunidades donde habitan, está dado por múltiples factores relacionados entre sí de manera única en cada persona, para que cada uno sea un elemento potencial de desarrollo sostenible en su territorio. 
Según Vázquez (2005) el uso de la potencialidad de desarrollo en un territorio puede conllevar a encontrar una mejor vía de desarrollo conforme a sus características. Esto está condicionado por la dinámica de aprendizaje que permita a los representantes locales la identificación de líneas de inversión eficientes.

Ante esta situación las localidades tienen como reto para su desarrollo intentar potencializar sus dimensiones económicas, sociales y medioambientales, buscando suplir sus carencias y necesidades sin perder su esencia cultural.

Este paso de una concepción del desarrollo que se trae desde afuera, al desarrollo construido y fortalecido a partir de las capacidades de los agentes personales y de las institucionales regionales, de una proximidad georreferenciar, organizacional e institucional, donde lo local es el eje y punto de convergencia entre territorio y desarrollo, corresponde al espacio donde los actores abandonan el papel de espectadores y asumen el rol de protagonistas de su destino común (Madoery, 2001). Esto indica que las experiencias de desarrollo local se constituyeron en nuevos modelos de diversificación de la economía en los distintos ámbitos territoriales, y para comprenderlas es necesario identificar las bases que las sustentan.

\section{Microcrédito: herramienta para el desarrollo local}

Como consecuencia de "la exclusión que los mercados de capital hacen de los países y sectores sociales más pobres" (Alonso, 1999, p. 8), se ha hecho necesario encontrar formas diferentes de concesión de créditos que respondan a estos requerimientos. De esta forma, en regiones de extrema pobreza surgen los programas de microcréditos como una alternativa para ayudar a las personas que se encuentran en esa situación, sin propiedades, pero con disposición e iniciativas para emprender una lucha contra la miseria; previendo cantidades pequeñas de dinero, que les permita financiar su iniciativa y mejorar su existencia, dándoles la oportunidad de vivir y mejorar sus condiciones de vida con su autoempleo (Vereda, 2001).

Las entidades microfinancieras, aparte de ser instituciones de crédito, tienen una gran orientación social. En este orden de ideas, fomentan innovadoras estrategias cuya finalidad es educar a los clientes en función del desarrollo económico, cambiar sus costumbres de comportamiento de tal forma que a largo plazo puedan alejarse de su situación de pobreza (Muriel, 2000). Para irse adaptando a las condiciones microempresariales del medio donde tienen asiento, han ido modificando y ajustando sus técnicas de intervención con el propósito de atender a los sectores de población de escasos recursos y sus requerimientos socioeconómicos más significativos (Foschiatto y Stumpo, 2006). Sin embargo, para Arango (citado por Serrano, Borgucci y Vera, 2013):

(...) las microfinanzas en Colombia se han reconocido por los programas de desarrollo local o regional con resultados no masivos y con participación del Estado, sólo como un veedor y no como interventor, específicamente sobre las tasas de interés y la asignación de los créditos, es decir, soporta los riesgos de las entidades en el país (p. 9).

Además, el éxito local de los propósitos de desarrollo requiere la creación y disposición de fuentes de riqueza en la región. Y para que aparezcan nuevos negocios o para 
que se desarrollen los ya existentes, es imprescindible contar con fuentes de financiación adecuadas (Unión Nacional de Cooperativas de Crédito-UNACC, 2001; Vázquez, 1999), que faciliten poner en marcha ideas de negocios sólidas y bien fundamentadas.

Existen escollos como los altos costos de transacción y la falta de garantías, que impiden el acceso de la población pobre a los servicios crediticios (Banco Mundial, 2008). La diversidad de problemas afecta su permanencia, al igual que su sostenibilidad y evolución en el tiempo, destacándose como uno de estos problemas el acceso a la financiación (De Asís, 2000; Foschiatto y Stumpo, 2006; García, 2004; Lacalle, 2008). Cabe indicar que, si bien esto no necesariamente puede que sea consecutivamente el principal obstáculo que afronten como sector, éste se convierte en un gran problema debido a la dificultad de entregar garantías que permitan el acceso al mercado financiero formal, siendo por tanto sujetos de tasas de interés altas (Herrera, 2003). Los programas de microcrédito surgieron con el objetivo social de luchar contra la pobreza, otorgándole financiación a los individuos más vulnerables de un territorio (Martin, 2007). Sin embargo, a través de los años han evolucionado de tal manera que actualmente existen programas de microcrédito dirigidos a financiar microemprendimiento que no están relacionados con pobreza extrema (Foschiatto y Stumpo, 2006; García, 2004).

A partir de este enfoque más amplio se puede caracterizar este nuevo instrumento de financiación y darle una mirada a algunos elementos que lo diferencian del crédito tradicional y el aporte que puede dar al desarrollo de un territorio en términos económicos y sociales. En otras palabras, la consideración en forma general de las microfinanzas, y por tanto el microcrédito, como un instrumento de fomento del desarrollo local. De allí lo considerado por Pérez, Hernández, Acosta y Chumaceiro (2009) y Gil, Castellanos y González (2019), que al ingresar nuevas entidades extranjeras al sector bancario desde el año 2014 con Mundo Mujer, de Chile, y el banco panameño Multibank, se favorecieron sectores del mercado de microcréditos como las Pymes, constituyéndose en un factor determinante para el crecimiento económico del país y con generación de empleo sustentable y de calidad.

De acuerdo con Vereda (2001), el microcrédito "es un instrumento mayoritario y eficaz capaz de financiar muchas de las tareas encaminadas a luchar contra la pobreza e iniciar el camino del desarrollo de los pueblos" (p. 88). Una caracterización más precisa y detallada la hace Lacalle, Rico y Durán (2008), para quien se caracteriza por:

a. La cuantía de los préstamos: corresponde a reducidas cantidades de dinero.

b. El tiempo: se otorgan a corto plazo.

c. Los periodos de devolución: el tiempo entre una devolución y otra, y los montos a devolver son reducidos.

d. Garantías: no se exigen avales al igual que garantías.

e. Actividades favorecidas: suelen ser micronegocios.

f. Inversión: se lleva a cabo en actividades escogidas de antemano por los propietarios.

La Tabla 1 muestra las características del crédito convencional y el microcrédito. 
TABLA 1.

Características distintivas de la microfinanciación

\begin{tabular}{|c|c|c|}
\hline & Crédito convencional & Microcrédito \\
\hline $\begin{array}{l}\text { Propiedad y forma de } \\
\text { gerencia }\end{array}$ & $\begin{array}{l}\text { Institución maximizadora } \\
\text { de beneficios y accionistas } \\
\text { individuales }\end{array}$ & $\begin{array}{l}\text { Bancos y ONGs. En el segundo caso } \\
\text { son principalmente organizaciones sin } \\
\text { ánimos de lucro }\end{array}$ \\
\hline Características del cliente & $\begin{array}{l}\text { Diversos tipos de empresas } \\
\text { formales y empleados } \\
\text { asalariados. Clientes } \\
\text { dispersos geográficamente }\end{array}$ & $\begin{array}{l}\text { Empresarios de bajo ingreso con firmas } \\
\text { familiares rudimentarias y limitada } \\
\text { documentación formal. Localizados en } \\
\text { áreas geográficas especificas }\end{array}$ \\
\hline Características del producto & $\begin{array}{l}\text { Montos grandes, largo plazo } \\
\text { y tasas de interés bajas }\end{array}$ & $\begin{array}{l}\text { Montos pequeños, corto plazo y tasas } \\
\text { de interés altas }\end{array}$ \\
\hline Metodología de préstamo & $\begin{array}{l}\text { Colateral y documentación } \\
\text { formal, pagos mensuales }\end{array}$ & $\begin{array}{l}\text { Análisis de deudor y de flujo de caja con } \\
\text { inspección en el sitio. Pago semanal o } \\
\text { bisemanal }\end{array}$ \\
\hline
\end{tabular}

Fuente: Jansson (2001).

En los últimos decenios las instituciones microfinancieras han mostrado un rápido crecimiento (Lacalle, 2002). La popularidad de estos programas se debe a sus peculiaridades, que han mostrado cierto atractivo para aquellas organizaciones que están implicadas en la cooperación internacional para el desarrollo (Mataix, 2000).

Para la UNACC (2001), un buen sistema de financiación orientado al desarrollo de las localidades debe involucrar tres aspectos que interactúen entre sí, dentro de un territorio y lo hagan de forma equilibrada: 1) Criterios para el desarrollo: considera la participación de los actores, equidad mediante una distribución equilibrada de los recursos y solidaridad a través de instrumentos políticos asistenciales regionales. 2) Actores locales implicados: corresponde a la administración regional que tiene como función principal la gestión de garantías, las entidades financieras gestionadoras de riesgos y los agentes particulares de la localidad tratando la innovación. 3) Requerimientos del capital financiero a nivel territorial: liquidez, seguridad y rentabilidad. Cómo puede apreciarse estos componentes aportan al desarrollo de un territorio en términos económicos y sociales, es decir, las microfinanzas actúan como un instrumento de fomento del desarrollo local.

Las experiencias a nivel local y nacional han facilitado la introducción del microcrédito, logrando que se abra paso en los tejidos productivos locales, con estrategias que permiten dinamizar la economía intracultural, con destino especialmente a unidades productivas caracterizadas por poseer en el núcleo familiar su propia base económica, financiera y social (Foschiatto \& Stumpo, 2006). Este es uno de los aspectos que hacen del microcrédito una herramienta potencialmente eficaz, por su capacidad para incorporarse en diferentes ramas de actividades económicas y para adaptarse metodológicamente a su dinámica. Esto les facilita el apoyo financiero a diferentes estratos socioeconómicos, especialmente a aquellos donde la banca tradicional no llega.

Otro de los aspectos que han favorecido la inclusión de los microcréditos en los territorios, es que se hayan tenido en cuenta en los planes de desarrollo local (Gutiérrez, 
2003), pudiendo contribuir a una mayor inclusión de desempleados y jóvenes en el mercado laboral, a una cultura y mayor espíritu empresarial, al acceso igualitario para hombres y mujeres a actividades empresariales, a una mayor y mejor integración de grupos marginados, al desarrollo de los mercados regionales y a organizar nuevos sectores a través de la promoción de actividades con alto potencial de desarrollo (UNACC, 2001).

La falta de acceso a recursos financieros en ocasiones genera al microempresario la pérdida de oportunidades para poner en marcha o mejorar sus actividades emprendedoras, y de paso el mejoramiento de su calidad de vida (Alonso, 1999). Es en este contexto donde se acoplan las necesidades de los microempresarios con los objetivos del microcrédito, lo que ha fortalecido las posibilidades de los programas de microcrédito como una forma de llegar y apoyar a las personas más pobres, pero con iniciativa y disposición para luchar contra el flagelo de la miseria, desarrollando sus ideas emprendedoras y viviendo de su autoempleo (Vereda, 2001).

Según Gulli (1999), el microcrédito puede ayudar en aspectos tales como: promover inversiones en diversos activos, proveer actividades para ganarse la vida; reducir la vulnerabilidad económica de las familias y mejorar la calidad de vida de las personas a través del mejoramiento de su dignidad, autoestima y poder de decisión. Bercovich (2004) hace énfasis en los aportes que pueden alcanzarse a través de la introducción de los microcréditos en las estrategias de desarrollo local: cultura empresarial y desarrollo de iniciativas empresariales y de mercados regionales, generación de empleo, menor exclusión social de los grupos marginados y avances de igualdad de oportunidades con menor diferencia de género en las actividades económicas.

Para Valentin (2017) el tema relacionado con el microfinanciamiento es de gran importancia y considera que este debe sobrepasar la simplicidad del deseo de combatir la pobreza y de apoyar y contribuir con aspectos del desarrollo local, debido a que resulta de un proceso de toma de decisiones que lleva consigo impactos multidimensionales. En este sentido Inglada, Sastre y de Miguel (2015) habían planteado que los microcréditos han traspasado las fronteras de los países pobres, implantándose en los más desarrollados lo que enfatiza el éxito de los mismos, dado a que los pobres están presentes en cualquier parte del mundo y sostienen que "el futuro de los microcréditos está tanto en los países en vías de desarrollo como en los del primer mundo" (p. 89).

En ese orden de ideas Pasquier (2015) sostiene que la difusión del microcrédito como estrategia para combatir la pobreza parte del supuesto que la pobreza es resultado de la exclusión de los servicios financieros formales, lo que conllevaría a que esta población haga uso de fuentes informales de créditos, perpetuando de esta forma la relación de dependencia.

Respecto a los tipos de créditos, Carpintero (1998) muestra la ventaja de distinguir entre dos:

1. Crédito de subsistencia: Tiene como objetivo mantener el funcionamiento del negocio. 
2. Crédito de desarrollo: Tiene como finalidad llevar a cabo acciones que contribuyan con el crecimiento del negocio. Para De Asis (2000) las diferencias principales entre estos tipos de créditos se relacionan con los plazos, la cantidad y fundamentalmente, en el objetivo perseguido por ellos. Pero, Yunus (2000) considera que independientemente de la procedencia, el crédito debe tener ordenamientos claros y previamente establecidos. Debe enmarcarse en una disciplina rígida, que no se confunda con la caridad, debido a que esta termina acabando la iniciativa, motivación y creatividad de los pobres. Clark y Kays (1995) sostienen que el microcrédito es un pequeño préstamo que se le ofrece a la microempresa y no a individuos pobres. Es esto lo que une el microcrédito con la microempresa, teniendo como punto central el uso empresarial que se le dé a los recursos y lo muestra como un instrumento idóneo de financiación, contra la pobreza y de promoción del desarrollo local.

Por su parte, Ferreira, Vacca, Guedes y Martirena (2011) sostienen que el manejo del microcrédito es un instrumento financiero utilizado en países latinoamericanos y europeos como estrategia de los Estados apuntándole al desarrollo y a la erradicación de la pobreza, a pesar que el concepto de pobreza varía en cada país, dependiendo de la postura de los prosistas en asuntos sociales. Citando a Lacalle (2008), sostienen García y Díaz (2011) que "los programas de microcréditos han demostrado ser efectivos en la lucha contra la pobreza de las mujeres" (p. 114), lo que ha permitido una mejora sostenida mediante la implantación de pequeñas empresas generando ingresos suficientes para las prestatarias, mejorando el nivel de vida del entorno familiar.

En ese orden de ideas Guevara (s.f) manifiesta que existe experiencia internacional que muestra el potencial de microempresas en la generación de empleo y mejoramiento de las condiciones de vida de grandes grupos de población en países en desarrollo. En tal sentido se afirma que "el microcrédito es un instrumento fundamental que presenta sostenibilidad y crecimiento masivo para el rescate económico y social de los excluidos de las redes de poder, es decir, aquellos que no pueden acceder a fuentes financieras tradicionales" (p. 9).

\section{Microcrédito y pobreza en Colombia}

Angelucci y De Giorgi (2006) consideran que los mayores ingresos de las familias beneficiadas por un crédito representan liquidez al mercado crediticio y que esto hace una especie de efecto dominó entre los miembros de la sociedad, de tal forma que las familias que no son beneficiarias de éstos solicitan dinero prestado a familiares, amigos o prestamistas informales. Esto explica, en parte, la proliferación de los microcréditos, por ser empréstitos que se adjudican a las personas más pobres a bajas tasas de interés y sin exigir garantía o aval (Yunus, 2000). Produciendo lo que Martínez, Palma, Flórez y Collinao (2013) llaman efecto imitación. Por lo que se podría esperar que el impacto de las entidades microfinancieras fuera mayor en aquellas localidades pequeñas o rurales donde todos se conocen.

De la mano de lo anterior Martínez, et al. (2013) piensan que entre las diferentes fuentes de ingreso de los hogares, las rentas del trabajo fueron determinantes en la 
explicación de la variación de los ingresos en los hogares pobres, ante la falta de empleo, la función de las entidades microfinancieras es fundamental como facilitadoras de capital inicial de trabajo para microempresarios o micro-emprendedores, por designar de algún modo a personas en condiciones de extrema pobreza pero con alguna iniciativa empresarial. Ya que como expresa Velázquez (2007), "los microcréditos se orientan a satisfacer las necesidades de financiamiento de los pequeños negocios y de las microempresas, y han demostrado ser una herramienta útil para reducir la pobreza" (p. 140). Martin (2007) asegura que en América Latina más de la mitad de la Población Económicamente Activa (PEA) trabaja en la economía informal. Por lo que destaca la importancia de promover las microfinanzas y de esta forma apoyar a ese ejército de microempresarios, a salir de la pobreza. Aspecto que es reforzado por Rodríguez (2010) al afirmar que "los microcréditos otorgados, parecen mejorar las condiciones de vida inmediatas de la población" (p. 115).

Marulanda y Otero (2005) proporcionan como ejemplo de lo anterior algunos estudios como los siguientes: el Banco Mundial en 1998 reveló que el 5\% de las prestatarias del Banco Grameen salen de la pobreza cada año; ACCIÓN indicó que el 60\% de los clientes de AGS (en Colombia) mejoraron su ingreso entre 10\% y 50\%. Lo que evidencia que se requiere de un mayor análisis del esfuerzo realizado por estas instituciones para entender su impacto en personas con pobreza o condiciones de vulnerabilidad a ésta.

$\mathrm{Al}$ respecto, al hacer un breve análisis del informe del DANE (2014) muestra como en Colombia el índice de pobreza bajó de 49,7\% en el año 2002 a 30,6\% en 2013 y el de indigencia de $17,7 \%$ a 9,1\% en el mismo periodo, es decir, el índice de pobreza cayó 19,1 puntos, mientras que el de indigencia cayó 8,6 puntos en el país entre 2002 y 2013. Para el año 2018 estos indicadores se situaron en $27 \%$ y 7,2\%, respectivamente (DANE, 2019). Mientras que en Sucre el índice de pobreza pasó de 69,2\% en 2002 a $47,3 \%$ en 2013 , y el de indigencia de $28,8 \%$ a $10,1 \%$ en el mismo periodo; para el 2018 los índices de pobreza bajaron al 41\% y 7,5\%, respectivamente. La cartera del microcrédito en Sucre pasó de $\$ 2.568 .000$ en 2002 a $\$ 120.204 .000$ en 2013 (DANE, 2015), logrando un aumento del $4.680,84 \%$ en ese periodo. Y aunque nadie puede garantizar que la disminución de la pobreza se deba a la inyección de microcréditos a las comunidades más pobres, hay ciertas coincidencias que llevan a pensar que las entidades microfinancieras tienen incidencia en la disminución de la pobreza en esta población, ello al tomar como evidencia de mucha credibilidad los destacado por Estrada y Hernández (2019) en el estudio que resaltan de la Fundación BBVA que al referirse al sector rural tan vulnerable con altos índices de pobreza enfatizan que:

(...) del porcentaje de clientes totales, el $44 \%$ pertenecen al entorno rural, $54 \%$ son mujeres, $79 \%$ se clasifican como vulnerables y $54 \%$ poseen educación primaria a lo sumo. La entidad estima que el buen desempeño de los negocios permite que, tras los dos primeros años de relación, el $48 \%$ de los clientes situados en pobreza logren superarla y pasados cinco años de la relación, esta cifra aumente hasta el $65 \%$. Así, el informe concluye que los clientes extremadamente pobres necesitan dos ciclos de microcrédito para superar la línea de pobreza, mientras que los clientes pobres consiguen superarla a partir del primer microcrédito (p. 97). 
El microcrédito puede concebirse como una importante herramienta financiera en la lucha contra la pobreza, cuando se puede acceder a él, y, por otro lado, promueve la creación de empleo, de patrimonio y la seguridad económica, lo que le da autonomía a los individuos que viven en determinado estado de pobreza, contribuyendo de paso a propiciar condiciones para tener una economía participativa, sin exclusión, y pueda verse reflejado en el crecimiento económico.

Desde otra perspectiva, el microcrédito contribuye a generar lazos de solidaridad, cohesión e integración social y participación comunitaria democrática; dinamiza las economías locales y es un buen insumo para promover la colaboración entre personas e instituciones comprometidas en el desarrollo económico (Rodríguez, 2010).

Entre las fuentes de ingreso de las familias en condiciones de vulnerabilidad, las rentas provenientes del trabajo fueron determinantes para explicar los cambios de los ingresos de dichas familias. Por lo que la función de las entidades microfinancieras es fundamental como facilitadoras de capital inicial de trabajo para microempresarios, orientado a satisfacer los requerimientos de financiamiento de las microempresas y de los pequeños negocios, como medio de apoyo para ayudar a estas personas a salir de la pobreza.

En una variedad de estudios cualitativos llevados a cabo en países de ingreso bajo, se evidenció que dos de las causas principales de que los individuos dejaran la pobreza eran alcanzar un empleo y poner en marcha un negocio. Evidentemente, en medio de las rápidas transformaciones económicas y sociales, en los países en desarrollo la pobreza se ha reducido. El porcentaje de los habitantes de las economías en desarrollo que viven con menos de US\$1,25 al día (sobre la base de la paridad del poder adquisitivo) pasó del 52\% en 1981 al 22\% en 2008, es decir, de 1940 millones de personas a 1290 millones (Banco Mundial, 2013, p. 7).

Rodríguez (2010) asegura que es significativo el porcentaje de beneficiarios de microcréditos que salen de la pobreza cada año en Colombia, por lo cual ha sido muy positivo el impacto de estas entidades en personas con altos índices de pobreza o condiciones de vulnerabilidad a ésta.

Además, en los informes de la Comision Economica para America Latina y el Caribe (Cepal, 2010; 2011; 2012; 2013) se evidencia que en las últimas dos décadas en Colombia los índices de pobreza e indigencia bajaron, ambos, alrededor de 20 puntos. Ello indudablemente tiene su relación con un desarrollo sostenible y duradero, tal como lo especifican en este sentido De La Hoz, De La Hoz, Escobar y Diaz (2018) en un proceso investigativo sobre desarrollo endógeno.

El Microcrédito es uno de los instrumentos más importantes que facilitan el acceso de las personas a los servicios financieros. Es fundamental tener en cuenta que a pesar que se ha generado un incremento significativo de cobertura en Colombia por el desarrollo de programas que tienden a incentivar el microcrédito, aún es insuficiente y los recursos estipulados distan mucho de ser significativos para contribuir con la reducción de la pobreza (Rodríguez, 2010). 


\section{Conclusiones}

El microcrédito como estrategia para mejorar situaciones específicas de la población clasificada como pobre, está inmerso en un tejido económico, social, cultural y reglamentario que influye significativamente en el impacto del mismo tejido o contexto, limitándolo o potenciándolo.

La importancia de las microfinanzas y su impacto, radica no sólo en los efectos sociales que puede generar, sino en que la oportunidad a acceder a los servicios microfinancieros puede promover el crecimiento económico y empresarial, lo que de paso ayuda a mejorar la fase del desarrollo económico. En este sentido, el impacto positivo implica mirar más allá del microcrédito, es decir, lo que este permite, como es el caso de la creación de unidades productivas y del conjunto de servicios asociados al mismo.

Otro aspecto a destacar del recorrido literario es que la parte de la población que vive en la pobreza, en condiciones menos severas, gozan de mayor potencial para aprovechar los beneficios que brinda el microcrédito. A ello se le suma que el impacto también depende de la esencia del programa microfinanciero en ejecución, cuyo direccionamiento puede ser el desarrollo empresarial, de los hogares, entre otros, sin que se desconozca su línea de tiempo.

Por otra parte, se tiene un crecimiento del mercado de las microfinanzas, toda vez que traspasa las fronteras de las regiones subdesarrolladas y es evidente el impacto que produce en torno al mejoramiento de las condiciones de vida de la población marginada que accede a ese mundo financiero.

Asimismo, se considera que el microcrédito permite tener capital de trabajo con bajo costo, ello al posibilitar la cualificación del capital humano en una organización que se beneficie de estas estrategias de financiación, posibilita la generación de beneficios que conducen a un desarrollo endógeno alrededor de la comunidad que se encuentre en los entornos donde operan las microempresas en las que se ha experimentado el uso del microcrédito.

\section{REFERENCIAS}

Alonso, J. A. (1999). La eficacia de la ayuda: Crónica de decepciones y esperanzas. Madrid: Civitas.

Angelucci, M. \& De Giorgi, G. (2006). Indirect effect of a aid program: The case of Progresa and consumption. IZA Discussion paper series, (1955), 1-47. Available from http://citeseerx.ist.psu.edu/viewdoc/summary?doi=10.1.1.222.5849

Banco Mundial. (2013). Informe sobre el desarrollo mundial. Washinton, D.C.:Banco Mundial.

Banco Mundial. (2008). Finance for all? Policies and pitfalls in expanding Access. [World Bank Policy Research Report]. Washington, D.C.: World Bank.

Bercovich, N. (2004). El microcrédito como componente de una politica de desarrollo local. [Serie Desarrollo Productivo No. 150]. Santiago de Chile: Cepal.

Berezo, J. (2005). Las microfinanzas en los países en desarrollo. Salamanca: Universidad Pontificia de Salamanca. 
Carpintero, S. (1998). Los programas de apoyo a la microempresa en América Latina. El microcrédito como la gran esperanza del siglo XXI. Bilbao: Deusto.

Casas, J. (2017). Implicaciones de los acuerdos del Fondo Monetario Internacional sobre la pobreza en Colombia. Económicas CUC, 38(1), 9-36. https://doi. org/10.17981/econcuc.38.1.01

Cepal. (2013). Panorama Social de América Latina. Santiago de Chile: Cepal. Cepal. (2012). Panorama Social de América Latina. Santiago de Chile: Cepal.

Cepal. (2011). Panorama Social de América Latina. Santiago de Chile: Cepal.

Cepal. (2010). Panorama Social de América Latina. Santiago de Chile: Cepal.

Clark, P. \& Kays, A. (1995). Enabling entrepreneurship: microenterprise developme in the United States. New York: Aspen Institute.

DANE. (2019). Boletín Técnico Pobreza Monetaria en Colombia, año 2018. Bogotá, D.C.: DANE.

DANE. (2015). Informe de coyuntura económica regional-ICER 2014-Departamento de Sucre. Bogotá, D.C.: DANE.

DANE. (2014). Boletín de prensa, Sucre: Pobreza monetaria 2013. Bogotá, D.C.: DANE.

De Asis, A. (2000). La microempresa y los programas de apoyo al sector microempresarial. En, A. De Asís, M. Labie, C. Mataix, C. y J. Sota, J., Las microempresas como agentes de desarrollo en el sur (pp. 17-47). Madrid: CIDEAL.

De la Hoz, A., De la Hoz, B., Escobar, A. y Díaz, A. (2018). Desarrollo endógeno comunitario producto de actividades de inversión en Ciencia, Tecnología e Innovación. Económicas CUC, 39(1). 61-74. http://dx.doi.org/10.17981/econcuc.39.1.2018.04

De La Torre, M. (2018). Utilización del sector financiero para el lavado de dinero: perspectiva desde la legislación ecuatoriana. Jurídicas CUC, 14(1), 145-166. https://doi.org/10.17981/juridcuc.14.1.2018.07

De Soto, H. (2008). Making the law for everyone. Report of the commission of legal empowerment of the poor. New York: United Nations Development Programm.

Estrada, D. y Hernández, A. (2019). Situación actual e impacto del microcrédito en Colombia. [Online]. Recuperado de https://repositorio.banrep.gov.co/bitstream/ handle/20.500.12134/9723/LBR_2019-07.pdf?sequence=8

Ferreira, A., Vacca, A., Guedes E. y Martirena, G. (noviembre, 2011). Herramientas financieras para el desarrollo rural: La experiencia del Proyecto Red de Desarrollo Local Villa del Rosario. Presentado al XI Congreso Iberoamericano de Extensión Universitaria, REXUNI, Santa Fé, Argentina.

Foschiatto, P. y Stumpo, G. (2006). El microcrédito: un instrumento para fortalecer las capacidades productivas locales. Santiago de Chile: Cepal.

García, A. (2004). Los micropréstamos como instrumentos de desarrollo en el sur: especial referencia al ámbito latinoamericano. Madrid: CIDEAL.

García, F. J. y Díaz, Y. (2011). Los microcréditos como herramienta de desarrollo: revisión teórica y propuesta piloto para el África Subsahariana. CIRIEC-España, Revista de Economía Pública, Social y Cooperativa, (70), 101-126. Recuperado de http://ciriec-revistaeconomia.es/wp-content/uploads/7005_Garcia_y_Diaz. pdf 
Gil, J., Castellanos, D. y Gonzáles, D. (2019). Margen de intermediación y concentración bancaria en Colombia: un análisis para el periodo 2000-2017. Económicas CUC, 40(2), 9-30. https://doi.org/10.17981/econcuc.40.2.2019.01

Guevara, L. (s.f.). Microfinanzas como herramienta para el desarrollo local. "El Caso AUGE”. Research Papers in Economics, 8-16. Recuperado de https://core.ac.uk/ reader/6868518

Gulli, H. (1999). Microfinanzas y pobreza. ¿Son válidas las ideas preconcebidas? Washington, D.C.: Banco Interamericano de Desarrollo-BID.

Gutiérrez, B. (2003). Microcrédito y desarrollo local. Revista Investigaciones y acciones sociales, (18), 115-128. https://doi.org/10.26754/ojs_ais/ais.200318265

Hernández, J. J., Ravina, R. \& Chumaceiro, A. C. (2020). Relevance and social responsibility of sustainable university organizations: analysis from the perspective of endogenous capacities. Entrepreneurship and Sustainability Issues, 7(4), 2967-2977. https://doi.org/10.9770/jesi.2020.7.4(26)

Herrera, J. (2003). Crédito a la Microempresa en Chile: una revisión cualitativa (1991-2001). Santiago de Chile: Programa de Economía del Trabajo-PET.

Inglada, M. E., Sastre, J. M. y de Miguel, M. C. (2015). Importancia de los microcréditos como instrumento de financiación en el desarrollo social. Revista Científica Guillermo de Ockham, 13(2), 89-100. https://doi.org/10.21500/22563202.2264

Jansson, T. (2001). Microcrédito y microfinanzas: ¿De la aldea a Wall Street? Washington D.C.: BID.

Lacalle, M. (2008). Microcréditos y pobreza. De un sueño al Nóbel de la Paz. Madrid: Turpial.

Lacalle, M. (2002). Microcréditos. De pobres a empresarios. Barcelona: Ariel.

Lacalle, M., Rico, S. y Duran, J. (2008). Estudio piloto de evaluacion de impacto del programa de microcréditos de Cruz Roja española en Ruanda. Revista de Economía Mundial, (19), 83-104. Disponible en http://rabida.uhu.es/dspace/hand$\mathrm{le} / 10272 / 589$

MacEwan, A. (2010). El significado de la pobreza: cuestiones de distribución y poder. Revista investigación económica, 69(272), 15-56. http://dx.doi.org/10.22201/ fe.01851667p.2010.272.24229

Madoery, O. (2001). El valor de la política de desarrollo local. En, A. Vázquez y O. Madoery (comp.), Transformaciones globales, instituciones y politicas de desarrollo local. Rosario: Homo Sapiens.

Martin, J. (2007). Del microcrédito a las microfinanzas. Revista de Empresa, (19), 99-102. Disponible en https://www.findevgateway.org/sites/default/files/publications/files/mfg-es-documento-del-microcredito-a-las-microfinanzas-2007.pdf

Martínez, L. (2006). Microcrédito y pobreza en Venezuela: un caso de estudio. Revista mexicana de ciencias politicas y sociales, (198), 95-112. http://dx.doi. org/10.22201/fcpys.2448492xe.2006.198.42541

Martínez, R., Palma, A., Flórez, L. y Collinao, M. (2013). El impacto económico de las politicas sociales. Santiago de Chile: Cepal.

Marulanda, B. y Otero, M. (2005). El perfil de las microfinanza en Latinoamérica en 10 años. Washington, D.C.: Acción. 
Mataix, C. (2000). Estrategias para el diseno de programas de promocion de microempresas. Madrid: CIDEAL.

Muriel, M. (2000). Microcrédito y pobreza: un ejercicio empírico sobre el impacto del Banco Grameen. Boletín ICE económico, (2659), 49-58.

Pasquier, A. (2015). Microcrédito y desarrollo rural. Una mirada crítica a partir de un estudio de caso. Revista Entre Diversidades, 1(5), 159-189. https://doi. org/10.31644/ED.5.2015.a06

Pérez, M. E., Hernández, J., Acosta, I. y Chumaceiro, A. (2009). Consideraciones teóricas para el análisis de las Pequeñas y Medianas Empresas como fuente de generación de empleo y su correspondencia ética con la Sociedad. Formación Gerencial, 8(2), 272-297. Disponible en https://produccioncientificaluz.org/index. $\mathrm{php} / \mathrm{rafg} / \mathrm{article} / \mathrm{view} / 623$

República de Colombia. DNP. (2012). Metodologías oficiales y arreglos institucionales para la medición de la pobreza en Colombia. [Documento Conpes Social 150]. Bogotá, D.C.: DNP, DANE, DPS. Recuperado de https://colaboracion.dnp.gov.co/ CDT/Conpes/Social/150.pdf

Rodríguez, M. (2010). El Microcrédito. Una Mirada hacia el concepto y su desarrollo en Colombia. Universidad Nacional de Colombia. [Tesis magistral]. UNAM, Bogotá, D.C., Colombia.

Sanhueza, P. (2013). Las microfinanzas como instrumento de apoyo al sector microempresarial en chile: estado y desafíos. Journal of Technology Management \& Innovation, 8(2), 209-220. https://doi.org/10.4067/S0718-27242013000200017

Serrano, M., Borgucci, E. y Vera, M. (2013). Estrategias de microfinanciamiento desarrolladas por la banca privada en Venezuela y Colombia. Revista Económicas CUC, 34(2), 115-130. Disponible en https://revistascientificas.cuc.edu.co/economicascuc/article/view/598

Torres, F. y Labarca, N. (2009). Construcción histórica-teórica del proceso de desarrollo económico. Revista de Ciencias Sociales, 15(3), 458-469. Disponible en https://produccioncientificaluz.org/index.php/rcs/article/view/25458

UNACC. (2001). Financiación del Desarrollo Local. Madrid: Unión Nacional de Cooperativas de Crédito.

Valentin, L. (2017). Desarrollo local y Microfinanzas como estrategias de atención a las necesidades locales: un acercamiento teorico conceptual. Revista Mexicana de Ciencias Políticas y Sociales, 62(229), 101-127. http://dx.doi.org/10.1016/ S0185-1918(17)30005-3

Vázquez, A. (2007). Sobre la diversidad de las interpretaciones y la complejidad del concepto de desarrollo endogeno. La Coruna: Netbiblo.

Vázquez, A. (2005). Las nuevas fuerzas del desarrollo. Barcelona: Antoni Bosch.

Vázquez, A. (1999). Desarrollo, redes e innovación. Lecciones sobre desarrollo endógeno. Madrid: Piramide.

Velázquez, J. (2007). El microcrédito: Sostenibilidad financiera vs. Impacto sobre la pobreza. Anales de la Universidad Metropolitana, 7(1), 139-155.

Vereda, A. (2001). Microcréditos y Desarrollo. Lima: FIDE. 
Vergara, P. (2004). ¿Es posible el desarrollo endogeno en territorios pobres y socialmente desiguales? Revista de Ciencias Sociales Online, 3(1), 37-52.

Yunus, M. (2000). Hacia un mundo sin pobreza. Barcelona: Andres Bello.

\section{BIODATA}

Diego Alfonso Ricardo Buelvas es Administrador de Empresas de la Universidad de Sucre (Colombia), Magister en Administración de la Universidad Nacional de Colombia y Jefe del Departamento de Administración de Empresas en la Universidad de Sucre. https://orcid.org/0000-0003-1830-8145.

León Julio Arango Buelvas es Economista de la Universidad de Cartagena (Colombia), Especialista en Gerencia Pública de la Universidad de Sucre (Colombia) con Magister en Ciencias Económicas de la Universidad Nacional de Colombia y Doctor en Ciencias Económicas de la Universidad del Zulia (Venezuela). Docente Asociado, Universidad de Sucre. https://orcid.org/0000-0001-8198-1872

Ramón José Taboada Hernández es Economista de la Universidad del Atlántico (Colombia); especialista en Gerencia de Mercadeo de la Universidad Jorge Tadeo Lozano (Bogotá, Colombia); Máster en Dirección Estratégica de Empresas de la Universidad de León (España). Docente por cátedras en Universidad de Sucre e investigador Junior en Colciencias. https://orcid.org/0000-0002-4029-8281 